\title{
Time for a More Holistic Approach to Peri- Pancreatoduodenectomy Care
}

\author{
Joseph R. Habib, MD, and Jin He, MD, PhD \\ Department of Surgery, Johns Hopkins University School of Medicine, Johns Hopkins Hospital, Baltimore, MD
}

The incidence of pancreatic cancer and premalignant pancreatic cystic neoplasms has increased dramatically during the past few decades. , ${ }^{2}$ For these patients, surgery, often via a pancreatoduodenectomy (PD), offers the best chance for cure or prevention of malignant transformation. Despite a historically high postoperative mortality rate, this complex operation is now relatively safe, with a recent mortality rate near $1 \%$ at high-volume centers. ${ }^{3}$ In parallel, more potent chemotherapy regimens have provided enhanced systemic control for patients with pancreatic ductal adenocarcinoma (PDAC). ${ }^{4}$ Consequently, these developments have expanded surgical candidacy and enabled more aggressive operative techniques. ${ }^{5},{ }^{6}$ All these advancements have finally brought the 5-year survival rate for PDAC into the double-digit territory (10\%). 'Taken together, the number of PDs and indications for this approach continue to increase, and an increasing proportion of post-PD patients are achieving long-term survival.

With this increase in long-term post-PD survivorship, an adaptation of care plans tailored toward addressing the postoperative psychosocial and physical needs of this growing population is imperative. In a recent study on the topic of this editorial, Ven Fong et al. ${ }^{7}$ at the Massachusetts General Hospital aimed to examine and better understand this population in this context. In their study, the authors deployed validated and pancreas-specific instruments to assess the various quality-of-life metrics for patients who

(C) Society of Surgical Oncology 2021

First Received: 2 March 2021

Accepted: 7 March 2021;

Published Online: 2 April 2021

J. He, MD, PhD

e-mail: jhe11@jhmi.edu survived at least 5 years after PD. They found that these long-term survivors had several residual digestive abnormalities as well as sexual and health care dissatisfaction.

Patients with a diagnosis of pancreatic cancer have been identified as a particularly vulnerable population. In a large study by Kent et al., patients with pancreatic cancer and multiple myeloma were found to have the worst mental and physical well-being outcomes. Another study demonstrated that patients with pancreatic cancer were more likely to experience anxiety and depression than patients with other malignancies.

The study by Fong et al. shows that even after "cure," residual quality-of-life concerns may persist 5 years after PD. Fong's group is to be applauded for their efforts to identify specific areas for improvement and patient support.

Interestingly, Fong et al. ${ }^{7}$ also found that health care satisfaction, particularly support from health care professionals and adequacy of information given to the patients about their condition and treatment, was significantly lower in the post-PD cohort. ${ }^{7}$ Admittedly, patients opting for surgical resection must accept a greater risk of postoperative complications and a decreased quality-of-life as a trade-off for a chance at long-term survival. As multidisciplinary care teams navigate these situations, a focus on enhancing patient support and an emphasis on patient education about the complications, outcomes, and longterm lifestyle expectations from the PD operation may partially diminish this issue.

The necessity to optimize communication and educational resources available to patients is underscored in a recent study by Khachfe et al. ${ }^{10}$ that showed a lack of highquality online information available to patients regarding PD. One pilot study found that an interdisciplinary supportive care-planning intervention involving educational sessions focused mainly on physical and psychosocial 
needs is feasible and acceptable for pancreatic cancer patients. " To improve care for this patient cohort, further intervention studies are warranted.

On a more positive note, post-PD patients were found to have a significantly lower prevalence of health worry and felt less limited in planning future activities. Furthermore, a staggering $88 \%$ of patients who underwent PD for cystic pancreatic neoplasms were happy with their decision to elect for surgery and reported that relief from the anxiety about harboring a potentially malignant lesion overshadowed post-PD lifestyle changes. These encouraging results are a reassuring sign as we turn our attention towards mitigating the adverse quality-of-life consequences associated with PD.

A concerted effort to raise physician and patient awareness with similar studies and to translate these findings into impactful modifications toward a more holistic approach to patient care is crucial as the prevalence of long-term post-PD patients is expected to rise continuously. Future trials investigating the impact of targeted interventions on patient care in this emergent population are needed so that surgeons may aspire to prolong life of the highest quality.

DISCLOSURES There are no conflicts of interest.

\section{REFERENCES}

1. Siegel RL, Miller KD, Fuchs HE, Jemal A. Cancer Statistics, 2021. CA Cancer J Clin. 2021;71:7-33. https://doi.org/10.3322/ caac.21654.

2. Valsangkar NP, Morales-Oyarvide V, Thayer SP, et al. 851 Resected cystic tumors of the pancreas: a 33-year experience at the Massachusetts General Hospital. Surgery. 2012;152(3 Suppl 1):S4-12. https://doi.org/10.1016/j.surg.2012.05.033.
3. Cameron JL, He J. Two thousand consecutive pancreaticoduodenectomies. J Am Coll Surg. 2015;220:530-6. https://doi.org/10. 1016/j.jamcollsurg.2014.12.031.

4. Conroy T, Hammel P, Hebbar M, et al. FOLFIRINOX or gemcitabine as adjuvant therapy for pancreatic cancer. $N$ Engl $\mathrm{J}$ Med. 2018;379:2395-406. https://doi.org/10.1056/NEJMoa1809775.

5. Hackert T, Sachsenmaier M, Hinz U, et al. Locally advanced pancreatic cancer: neoadjuvant therapy with folfirinox results in resectability in 60\% of the patients. Ann Surg. 2016;264:457-63. https://doi.org/10.1097/SLA.0000000000001850.

6. Habib JR, Kinny-Köster B, van Oosten F, et al. Periadventitial dissection of the superior mesenteric artery for locally advanced pancreatic cancer: surgical planning with the "halo sign" and "string sign." Surgery. 2020. https://doi.org/10.1016/j.surg.2020. 08.031.

7. Fong ZV, Sekigami Y, Qadan M, et al. Assessment of the longterm impact of pancreatoduodenectomy on heath-related quality of life using the EORTC QLQ-PAN26 module. Ann Surg Oncol. 2021. https://doi.org/10.1245/s10434-021-09853-8.

8. Kent EE, Ambs A, Mitchell SA, Clauser SB, Smith AW, Hays RD. Health-related quality of life in older adult survivors of selected cancers: data from the SEER-MHOS linkage. Cancer. 2015;121:758-65. https://doi.org/10.1002/cncr.29119.

9. Zabora J, BrintzenhofeSzoc K, Curbow B, Hooker C, Piantadosi $\mathrm{S}$. The prevalence of psychological distress by cancer site. Psychooncology. 2001;10:19-28. https://doi.org/10.1002/10991611(200101/02)10:1\%3c19::aid-pon501\%3e3.0.co;2-6.

10. Khachfe HH, Chahrour MA, Habib JR, Yu J, Jamali FR. A quality assessment of the information accessible to patients on the Internet about the Whipple procedure. World J Surg. 2021. h ttps://doi.org/10.1007/s00268-021-05989-6.

11. Sun V, Ruel N, Chung V, et al. Pilot study of an interdisciplinary supportive care planning intervention in pancreatic cancer. Support Care Cancer. 2016;24:3417-24. https://doi.org/10.1007/ s00520-016-3155-9.

Publisher's Note Springer Nature remains neutral with regard to jurisdictional claims in published maps and institutional affiliations. 